\title{
Faktor Risiko Sakit Tuberkulosis pada Anak yang Terinfeksi Mycobacterium Tuberculosis
}

\author{
Kamalina Yustikarini, Magdalena Sidhartani \\ Departemen Ilmu Kesehatan Anak Fakultas Kedokteran Universitas Diponegoro/ RSUP Dr. Kariadi, Semarang
}

Latar belakang. Tuberkulosis (TB) masih merupakan masalah kesehatan dan penyebab utama mortalitas dan morbiditas pada anak. Anak yang terpapar Mycobacterium Tuberculosis mempunyai risiko tinggi menjadi sakit TB. Terdapat beberapa faktor risiko yang berpengaruh terhadap sakit TB pada anak

Tujuan. Mengetahui faktor risiko yang berpengaruh terhadap sakit TB anak

Metode. Rancangan penelitian kasus kontrol, subjek penelitian terdiri atas 40 anak sakit TB sebagai kelompok kasus dan 40 anak infeksi TB sebagai kelompok kontrol. Diagnosis ditegakkan dengan menggunakan sistem skoring TB. Faktor risiko yang diteliti meliputi riwayat kontak, usia, imunisasi BCG, kepadatan hunian, sosial ekonomi, dan pengetahuan. Analisis statistik menggunakan uji chi square untuk analisis bivariat dan regresi logistik untuk analisis multivariat.

Hasil. Delapan puluh anak diikutsertakan dalam penelitian, median usia 49,5 bulan (12-156 bulan). Hasil uji statistik menunjukkan bahwa tidak terdapat hubungan bermakna antara usia, imunisasi BCG, status sosial ekonomi dan pengetahuan dengan kejadian TB pada anak. Terdapat hubungan yang bermakna riwayat kontak TB dengan sakit TB OR 18,3 (IK95\% 5,12-65,89; p<0,05). Kepadatan hunian dengan kejadian sakit TB OR 6,54 (IK95\% 1,05-40,73; p<0,05).

Kesimpulan. Riwayat kontak TB dan kepadatan hunian merupakan faktor risiko sakit TB pada anak. Usia muda, imunisasi BCG, status sosial-ekonomi dan pengetahuan tidak terbukti sebagai faktor risiko kejadian sakit TB pada anak yang terinfeksi Mycobacterium Tuberculosis. Sari Pediatri 2015;17(2):136-40.

Kata kunci: tuberkulosis, faktor risiko

\section{Risk Factors for Tuberculosis among Children Infected with Mycobacterium Tuberculosis}

\author{
Kamalina Yustikarini, Magdalena Sidhartani
}

\begin{abstract}
Background. Tuberculosis (TB) is a major public health problem and cause a high morbidity and mortality in children. Children exposed to Mycobacterium tuberculosis have a high risk for developing tuberculosis disease. There are many risk factors associated with TB in children Objective. To determine the risk factors for tuberculosis disease development in children.

Methods. A case control study was done with 40 cases with TB disease and 40 control infected with TB. Pulmonary tuberculosis was diagnosed using the Indonesian Pediatric Tuberculosis Scoring System. Risk factors for tuberculosis development were history of contact with a TB patient, age, BCG immunization, knowledge, socioeconomic status and overcrowding living condition. Analysis was done using chi square test and logistic regression.

Results: Eighty children were included in the study with median age were 49.5 months (12-156 months). There was no statistically significant difference for age, BCG immunization, social-economic status and knowledge of TB development in children. History of contact with TB patient was statistically significantly different for children with TB disease, with OR 18.3 (CI 95\% 5.12-65.89; $\mathrm{p}<0.05$ ). Overcrowding living condition was another risk factor for TB development in children, with OR 6.54 (CI 95\% 1.05- 40.73; $\mathrm{p}<0.05$ ). Conclusion: History of contact with TB patient and overcrowding living condition were risk factors for TB disease development in children. Age, BCG immunization, social-economic status and knowledge about TB were not risk factors for TB disease development in children. Sari Pediatri 2015;17(2):136-40.
\end{abstract}

Keywords: tuberculosis, risk factors, children

Alamat korespondensi: Dr. Kamalina Yustikarini, Sp-A; Prof. Dr. Magdalena Sidhartani, Sp-A(K), Bagian IKA FK-UNDIP/RSUP Dr. Kariadi. Jl. Dr. Soetomo No. 16-18 E-mail : kamalinayustikarini@ymail.com 
$\mathrm{T}$ uberkulosis (TB) masih merupakan masalah kesehatan di seluruh dunia. Saat ini, TB telah menjadi ancaman global oleh karena morbiditas dan mortalitas yang tinggi, terutama pada negara yang sedang berkembang, termasuk Indonesia. Data WHO tahun 2007 menyatakan bahwa Indonesia menempati posisi tiga di dunia setelah India dan China. Insiden tuberkulosis sekitar 528 ribu kasus dengan jumlah kematian sekitar 91.369 orang pertahun. ${ }^{1}$ Dari seluruh prevalensi tuberkulosis, kejadian sakit tuberkulosis pada anak 15\%. ${ }^{1-3}$ Data Dinas Kesehatan Kota Semarang tahun 2010 menemukan 15\% kasus sakit tuberkulosis anak dari semua kasus TB. ${ }^{4}$

Anak yang terinfeksi TB tidak selalu akan mengalami sakit TB, 10\%-15\% yang terinfeksi TB akan menjadi sakit TB. Pemberian terapi pencegahan pada anak infeksi TB mengurangi kemungkinan berkembangnya sakit TB. Anak yang terinfeksi tuberkulosis dapat memperlihatkan hasil uji tuberkulin positif tanpa ditemukan kelainan manifestasi klinis, radiologis, ataupun laboratorium. Anak yang sudah terinfeksi TB harus dicegah untuk berkembang menjadi sakit tuberkulosis. ${ }^{1,2}$ Faktor yang memengaruhi seseorang anak sakit $\mathrm{TB}$ adalah daya tahan tubuh yang lemah, sosial dan ekonomi yang rendah, kemiskinan, perumahan yang kurang memenuhi syarat kesehatan, kepadatan penduduk, besar keluarga, gizi kurang, serta kebersihan lingkungan. Disamping itu, ada faktor lain, seperti sumber penularan penyakit, usia, tidak mendapat imunisasi, virulensi serta jumlah kuman memegang peran penting dalam sakit TB paru. ${ }^{5,6} \mathrm{Pada}$ tahun 2010, di Semarang, tercatat cukup banyak kasus TB usia di bawah 5 tahun atau balita dan mengalami peningkatan dari 4,7\% dari tahun 2009 menjadi 8,7\% pada tahun 2010. Diperkirakan kasus TB pada anak di masyarakat masih cukup banyak dan perlu dilakukan penelitian lebih lanjut. ${ }^{4}$ Oleh karena itu, penelitian ini dilakukan untuk mengetahui faktor risiko yang memengaruhi sakit TB pada anak yang terinfeksi Mycobacterium Tuberculosis sehingga dapat dilakukan pencegahan agar tidak menjadi sakit $\mathrm{TB}$

\section{Metode}

Penelitian observasional dengan rancangan kasus kontrol dilakukan di Balai Kesehatan Paru Masyarakat di kota Semarang pada Agustus 2012 - Maret 2014.
Subyek penelitian 80 anak usia 1-14 tahun, 40 sakit TB sebagai kelompok kasus dan 40 infeksi TB kelompok kontrol. Kriteria inklusi kasus adalah anak dengan uji tuberkulin $\geq 10 \mathrm{~mm}$, usia 1-14 tahun, diagnosis skoring $\mathrm{TB} \geq 6$, orangtua mengizinkan anaknya masuk dalam penelitian. Kriteria eksklusi kasus adalah menderita kelainan sistem imun, misalnya HIV, keganasan, dan penyakit jantung. Kriteria inklusi kontrol adalah anak yang terinfeksi TB dengan uji tuberkulin positif $\geq 10 \mathrm{~mm}$ dan tidak sakit TB berumur 1-14 tahun. Variabel bebas adalah usia muda, belum imunisasi BCG, pengetahuan orang tua rendah, sosial ekonomi kurang, kepadatan hunian, dan riwayat kontak TB. Variabel terikat adalah sakit TB pada anak. Kepadatan hunian dinyatakan sebagai luas lantai seluruh ruangan dibagi jumlah penghuni minimal $10 \mathrm{~m}^{2} /$ orang. ${ }^{15}$ Pemilihan subyek penelitian secara consecutive sampling. Dilakukan anamnesis dan pemeriksaan fisik, status gizi, foto torax posisi PA dan lateral. Uji tuberkulin dilakukan pada kelompok kasus maupun kelompok kontrol. Dilakukan oleh dokter dan perawat yang sudah dilatih dan memiliki kompetensi yang baik. Uji tuberkulin positif menunjukkan adanya infeksi TB. Diagnosis tuberkulosis ditegakkan dengan metode skoring. Sistem skoring diagnosis tuberkulosis anak meliputi kontak TB, uji tuberkulin, status gizi, demam $\geq 2$ minggu tanpa sebab jelas, batuk $\geq 3$ minggu, pembesaran kelenjar limfe, pembengkakan sendi/ tulang, foto dada. Sistem skoring TB berdasarkan wawancara dilakukan oleh dokter yang sudah dilatih dan peneliti meliputi kontak BTA positif dan gejala TB serta penelusuran faktor risiko dengan menggunakan kuesioner. Penelitian ini telah mendapat persetujuan dari Komite Etik Penelitian Kedokteran Fakultas Kedokteran Universitas Diponegoro /RSUP Dr. Kariadi Semarang No 234/EC/FK/RSDK/2013. Analisis statistik dengan chi square dan regresi logistik. Nilai $\mathrm{p}<0,05$ dianggap bermakna.

\section{Hasil}

Subyek penelitian adalah 80 anak usia 1-14 tahun, 40 sakit TB sebagai kelompok kasus dan 40 infeksi TB sebagai kelompok kontrol. Karakteristik subyek penelitian tertera pada Tabel 1 . Tabel 2 menunjukkan bahwa berdasarkan sistem skoring TB didapatkan riwayat kontak dan batuk $\geq 3$ minggu pada kelompok kasus lebih banyak dibandingkan kelompok kontrol. 
Tabel 1. Karakteristik subjek penelitian

\begin{tabular}{lcc}
\hline Karakteristik & $\begin{array}{c}\text { Kasus } \\
\mathrm{n}(\%)\end{array}$ & $\begin{array}{c}\text { Kontrol } \\
\mathrm{n}(\%)\end{array}$ \\
\hline $\begin{array}{l}\text { Jenis kelamin } \\
\text { Laki laki }\end{array}$ & $16(40)$ & $15(37,5)$ \\
$\quad \begin{array}{l}\text { Perempuan } \\
\text { Pendidikan ayah }\end{array}$ & $24(60)$ & $25(62,5)$ \\
$\quad$ Buta huruf-SD & $4(10)$ & $1(2,5)$ \\
SLTP & $7(17,5)$ & $9(22,5)$ \\
SLTA & $25(62,5)$ & $22(55)$ \\
Akademi & $4(10)$ & $8(20)$ \\
Pendidikan ibu & & \\
Buta huruf-SD & $4(10)$ & $2(5)$ \\
SLTP & $10(25)$ & $12(30)$ \\
SLTA & $20(50)$ & $19(47,5)$ \\
Akademi & $6(15)$ & $7(17,5)$ \\
\hline
\end{tabular}

Dari analisis bivariat tidak ada perbedaan yang bermakna terhadap imunisasi BCG, pengetahuan orangtua, dan sosial ekonomi. Tiga variabel yang bermakna terhadap kejadian sakit TB, yaitu usia, kepadatan hunian, riwayat kontak. Dengan demikian, variabel yang layak diikutkan dalam analisis multivariat adalah tiga variabel.

Hasil analisis multivariat mendapatkan bahwa riwayat kontak merupakan faktor risiko terhadap
Tabel 2. Karakteristik TB berdasar sistem skoring

\begin{tabular}{lcc}
\hline Gejala & $\begin{array}{c}\text { Kasus } \\
\mathrm{n}(\%)\end{array}$ & $\begin{array}{c}\text { Kontrol } \\
\mathrm{n}(\%)\end{array}$ \\
\hline $\begin{array}{cc}\text { Demam } \geq 2 \text { minggu tanpa sebab jelas } \\
\text { Ya }\end{array}$ & $\begin{array}{c}8(20) \\
\text { Tidak }\end{array}$ & $0(0)$ \\
Batuk $\geq 3$ minggu & $32(80)$ & $40(100)$ \\
Ya & & \\
Tidak & $29(72,5)$ & $2(5)$ \\
Status gizi (\%) & $11(27,5)$ & $38(95)$ \\
Kurang & $23(57,5)$ & $14(35)$ \\
Baik & $17(42,5)$ & $26(65)$ \\
Riwayat kontak & & \\
Ada & $28(70)$ & $4(10)$ \\
Tidak ada & $12(30)$ & $36(90)$ \\
Pembesaran kelenjar limfa & & \\
Ya & $18(45)$ & $4(10 \%)$ \\
Tidak & $22(55)$ & $36(90 \%)$ \\
Pembengkakan sendi & & \\
Ya & $0(0)$ & $0(0)$ \\
Tidak & $40(100)$ & $40(100)$ \\
X foto thorax & & \\
Tersangka TB & $8(20)$ & $0(0)$ \\
Bukan tersangka TB & $32(80)$ & $40(100)$ \\
\hline & & \\
\hline & & \\
& &
\end{tabular}

kejadian sakit TB pada anak dengan TB OR 18,3 (IK95\%:5,12-65,89; p<0,05). Kepadatan hunian merupakan faktor risiko terhadap kejadian sakit TB

Tabel 3. Hasil analisis bivariat faktor risiko sakit TB pada anak

\begin{tabular}{|c|c|c|c|c|c|c|}
\hline \multirow[b]{2}{*}{ Variabel bebas } & \multirow{2}{*}{$\begin{array}{l}\text { Kasus } \\
\mathrm{N}(\%) \\
\end{array}$} & \multirow{2}{*}{$\begin{array}{c}\text { Kontrol } \\
\text { N (\%) }\end{array}$} & \multirow[b]{2}{*}{ OR } & \multicolumn{2}{|c|}{ IK95\% } & \multirow[b]{2}{*}{$\mathrm{p}$} \\
\hline & & & & Batas bawah & Batas atas & \\
\hline \multicolumn{7}{|c|}{ Usia (\%, tahun) } \\
\hline$<5$ & $27(67,5)$ & $18(45)$ & 2,53 & 1,02 & 6,29 & 0,043 \\
\hline$>5$ & $13(32,5)$ & $22(55)$ & & & & \\
\hline \multicolumn{7}{|c|}{ Imunisasi BCG (\%) } \\
\hline Tidak & $8(20)$ & $4(10)$ & 2,25 & 0,61 & 8,18 & 0,210 \\
\hline Ya & $32(80)$ & $36(90)$ & & & & \\
\hline \multicolumn{7}{|c|}{ Kepadatan hunian (\%) } \\
\hline Padat & $38(95)$ & $27(67,5)$ & 9,14 & 1,90 & 43,89 & 0,002 \\
\hline Tidak padat & $2(5)$ & $13(32,5)$ & & & & \\
\hline \multicolumn{7}{|c|}{ Tingkat sosial ekonomi (\%) } \\
\hline Kurang & $15(37,5)$ & $8(20)$ & 2,40 & 0,87 & 6,55 & 0,084 \\
\hline Cukup & $25(62,5)$ & $32(80)$ & & & & \\
\hline \multicolumn{7}{|c|}{ Tingkat pengetahuan (\%) } \\
\hline Kurang & $11(27,5)$ & $8(20)$ & 1,51 & 0,53 & 4,29 & 0,431 \\
\hline Cukup & $29(72,5)$ & $32(80)$ & & & & \\
\hline \multicolumn{7}{|c|}{ Riwayat kontak (\%) } \\
\hline Ada & $28(70)$ & $4(10)$ & 21,00 & 6,11 & 72,18 & 0,000 \\
\hline Tidak ada & $12(30)$ & $36(905)$ & & & & \\
\hline
\end{tabular}


Tabel 4 Hasil analisis multivariat

\begin{tabular}{|c|c|c|c|c|}
\hline \multirow[b]{2}{*}{ Variabel bebas } & \multirow{2}{*}{ OR } & \multicolumn{2}{|c|}{ IK95\% } & \multirow{2}{*}{$\mathrm{p}$} \\
\hline & & Batas bawah & Batas atas & \\
\hline Riwayat kontak TB & 18,37 & 5,12 & 65,89 & 0,000 \\
\hline Kepadatan hunian & 6,54 & 1,05 & 40,73 & 0,044 \\
\hline
\end{tabular}

pada anak dengan OR 6,54 (IK95\%:1,05-40,73; $\mathrm{p}<0,05)$.

\section{Pembahasan}

Pada penelitian ini didapatkan kepadatan hunian sebagai faktor risiko sakit TB pada anak. Kepadatan hunian dapat meningkatkan risiko sakit TB karena memperbesar terjadi penyebaran infeksi kuman TB antar anggota keluarga. Kuman penyebab TB mudah ditularkan lewat udara melalui droplet di dalam ruangan yang padat dan ventilasi yang tidak memadai sehingga kuman TB akan mudah menular kepada anggota keluarga yang lain. Kepadatan hunian dan ventilasi yang kurang berkontribusi terhadap penyebaran TB. ${ }^{7}$ Anak dengan hunian yang padat berisiko lima kali terinfeksi TB. ${ }^{8}$

Infeksi TB sering terjadi pada masa kanak-kanak dan anak dengan infeksi TB berisiko tinggi sakit $\mathrm{TB}$, yang paling rentan anak usia $<5$ tahun. ${ }^{3}$ Dalam penelitian ini didapatkan anak usia $<5$ tahun memiliki persentase yang lebih tinggi dibandingkan usia $>5$ tahun, meskipun perbedaan antara kasus dan kontrol tidak bermakna. Anak usia $<5$ tahun mempunyai risiko lebih besar mengalami progresi infeksi menjadi sakit TB karena imunitas selular yang belum sempurna. ${ }^{9}$ Penelitian Shinfield $\mathrm{dkk}^{10}$ menunjukkan bahwa anak yang terpajan kontak dengan BTA (+) 60\%-80\% terinfeksi TB. Risiko kejadian sakit TB pada anak lebih tinggi pada usia $<5$ tahun.

Dari hasil penelitian ini didapatkan tidak ada hubungan antara status imunisasi BCG dengan sakit TB pada anak. Didapatkan sebagian besar subyek sudah imunisasi BCG, skar BCG pada kelompok kasus 32 (80\%) dan kelompok kontrol 37 (92,5\%) anak. Di Pakistan, Zafar ${ }^{11}$ melaporkan bahwa skar BCG bukan merupakan faktor risiko independen untuk terinfeksi atau sakit TB. Efektifitas imunisasi BCG untuk mencegah TB primer bervariasi antara $0 \%-80 \%$. Vaksin BCG tidak dapat memproteksi secara penuh kemungkinan terjadi infeksi TB, sekitar 68,6\% yang diimunisasi BCG terinfeksi TB. Data meta-analisis dari 14 penelitian prospektif dan 12 studi kasus-kontrol tentang efektifitas imunisasi BCG menunjukkan bahwa BCG secara bermakna mengurangi risiko TB, dengan rata-rata $50 \% \cdot{ }^{12}$ Michelsen $\mathrm{dkk}^{13}$ mendapatkan temuan yang sama bahwa BCG mengurangi risiko TB dengan efektifitas 50\%. Imunitas yang terbentuk tidaklah menjamin tidak terjadi infeksi TB pada seseorang, tetapi bila terjadi infeksi tidak progresif dan tidak menimbulkan komplikasi yang berat. ${ }^{12}$

Dari hasil penelitian ini tidak didapatkan hubungan antara status sosial ekonomi dengan sakit TB. Hal tersebut terjadi karena pada 65\% kasus dan $82,5 \%$ kontrol bukan keluarga miskin. Penelitian kami mendapatkan status sosioekonomi tidak berperan terhadap sakit TB anak. Didapatkan 72,5\% kasus dan $80 \%$ kontrol memiliki pengetahuan cukup tentang TB secara umum, tetapi tidak bermakna secara statistik. Dalam kaitannya dengan sosial ekonomi, seseorang dengan tingkat ekonomi dan pengetahuan cukup jika tanpa diikuti sikap dan perilaku yang sesuai tidak akan banyak berpengaruh terhadap sakit TB.

Setiap kasus tuberkulosis pada anak disebabkan kontak dengan orang yang terinfeksi. Faktor lain adalah jumlah orang serumah, lamanya tinggal serumah, dan satu kamar dengan penderita TB..$^{13,15}$ Pada penelitian ini didapatkan riwayat kontak dengan BTA positif pada kasus lebih tinggi dibanding kontrol. Penelitian ini menunjukkan kejadian sakit TB pada anak yang memiliki kontak dekat dengan TB dewasa dengan BTA positif. Singh $\mathrm{dkk}^{14}$ menyatakan bahwa dari 95 anak yang memiliki kontak dekat dengan pasien TB dewasa dengan BTA positif, 65 anak terinfeksi TB. Hasil penelitian Abassi $\mathrm{dkk}^{16}$ menunjukkan bahwa $80 \%$ dari populasi penelitian memiliki riwayat kontak dekat dengan kasus TB. Penelitian Nguyen $\mathrm{dkk}^{2}$ menemukan bahwa kontak dengan seorang TB dewasa dengan BTA (+) merupakan faktor risiko untuk infeksi TB. Perbedaan ini dapat dijelaskan oleh lamanya paparan serta virulensi M.tbc dari individu dengan TB. ${ }^{14,17}$. 
Keterbatasan pada penelitian ini adalah bias recall dapat terjadi dari subyek penelitian karena perbedaan kemampuan pasien mengingat informasi. Interviewer bias terjadi karena subyektifitas atau sugesti pewawancara. Bias intra-observer hasil radiologis dalam pembacaan hasil foto toraks. Bias pengukuran terhadap pembacaan hasil uji tuberkulin pada subjek penelitian. Pada penelitian ini diupayakan dengan pembacaan hasil uji tuberkulin oleh peneliti, dokter, dan atau perawat yang sudah dilatih dengan menggunakan alat ukur yang sama. Namun, pada penelitian ini tidak dilakukan uji kesesuaian antar pemeriksa.

\section{Kesimpulan}

Riwayat kontak TB dan kepadatan hunian merupakan faktor risiko yang berpengaruh terhadap kejadian sakit $\mathrm{TB}$, sedangkan usia muda, imunisasi BCG, status sosial-ekonomi, dan pengetahuan tidak terbukti sebagai faktor risiko kejadian sakit TB pada anak yang terinfeksi M.tuberculosis.

\section{Daftar pustaka}

1. WHO. Guidance for national tuberculosis programmes on the management of tuberculosis in children. Second Edition. Geneva; WHO.2014.h.1-146.

2. Nguyen TH, Odermatt P, Slesak G, Barennes H. Risk of latent tuberculosis infection in children living in households with tuberculosis patients: a cross sectional survey in remote northern Lao People's Democratic Republic. BMC Infect Dis 2009;9:96-101.

3. Nakaoka H, Lawson L, Squire SB, Coulter B, Ravn P, Brock I, dkk. Risk for tuberculosis among children. Emerg Infect Dis 2006;12:1383-8.

4. Dinas Kesehatan Provinsi Jawa Tengah. Laporan program P2 TB paru. Dalam: Hasil kegiatan tahun 2010 dan rencana kerja 2011. Semarang: Dinkes Prov JATENG;2010:64.

5. Rahajoe NN, Basir D, MS Makmuri, Kartasasmita CB. Pedoman Nasional Tuberkulosis Anak. Edisi ke-2. Jakarta: UKK Respirologi IDAI;2007.h.1-147.
6. Setyanto DB, Rahajoe NN. Diagnosis tuberkulosis pada anak. Dalam: Rahajoe NN, Supriyatno B, Setyanto DB, penyunting. Buku Ajar Respirologi Anak. Edisi ke-1. Jakarta: IDAI.2008.h.200-11.

7. Advisory Commitee Statements. Housing conditions that serve as risk factors for tuberkulosis infection and disease. Canadian Comunicable Disease Report 2007; 33;1-10.

8. Karim MR, Rahmana M, Shaikh AA, Mamunb SA, Alama MA, Akhter S. Risk factors of childhood tuberculosis: a case control study from rural Bangladesh. WHO South-East Asia. J Pub Health 2012;1:76-84.

9. Narasimhan P, Wood J, Mathai D. Risk factors for tuberculosis. Pulmo Med 2013;1-13.

10. Sinfield R, Nyirenda M, Haves S, Moly M, Graham $\mathrm{M}$. Risk factors for TB infection and disease in young childhood contacts in Malawi. Ann Trop Paediatr 2006;26: 205-13.

11. Zafar M. Prevelence of latent tuberculosis and associated risk factors in children under 5 years of age in Karachi, Pakistan. J Assoc of Chest Physicians 2014;2:16-24.

12. Brewer FT. Preventing tuberculosis with bacillus calmette-gue' rin vaccine: a meta-analysis of the literature. Clin Infect Dis 2000;31:64-7.

13. Michelsen SW, Soborg B, Koch A, Carstensen L, Hoff ST, Agger EM, dkk. The effectiveness of BCG vaccination in preventing Mycobacterium tuberculosis infection and disease in Greenland. Thorax 2014;69:851-6.

14. Singh M, Mynak ML, Kumar L, Mathew JL, Jindal SK. Prevalence and risk factors for transmission of infection among children in household contact with adults having pulmonary tuberculosis. Arch Dis Child 2005;90:624-8.

15. Menteri Kesehatan RI. Keputusan Menteri Kesehatan Republik Indonesia No.829/MenKes/SK/VII/1999 tentang Persyaratan Kesehatan Perumahan.

16. Abassi S, Hussain M, Krishin J, Sami-ul-haq. Risk factors of tuberculosis in children. Ann Park Ins Med Sci 2010;6;50-4.

17. Linhardt C, Bennet S, Prete DG, Bah-sow O, Newport $\mathrm{M}$, Gustafson P dkk. Investigation of environmental and host related risk factors for tuberculosis in Africa. Methodological aspects of a combined design. Am J Epidemiol 2002;155;1066-73. 